\title{
O CAMPO ORGANIZACIONAL DAS ÁGUAS BRASILEIRAS: A FORMAÇÃO HISTÓRICA DE UMA MENTALIDADE
}

\author{
The Organizational Field of Brazilian Waters: The Historical Formation of a Mentality
}

\begin{abstract}
RESUMO
O presente trabalho vislumbrou tece um panorama do campo organizacional das águas no Brasil, de maneira a identificar as raízes de suas peculiaridades. Para tanto, adotou-se a revisão historiográfica como método analítico, seguindo o esforço do movimento por mais história nos Estudos Organizacionais. Assim, os marcos históricos apontados em nossa revisão foram avaliados a partir da concepção predominante de cada época. Neste sentido, esta trajetória revela diferentes concepções, indo da ideia de que a água é um recurso abundante e inesgotável, um fator estratégico para a industrialização, um recurso exclusivo da União para uma questão de múltiplos usos e interesses.
\end{abstract}

Mayla Cristina Costa

Universidade Federal do Paraná

mayla.c.costa@gmail.com

Fábio Vizeu

Universidade Positivo

fabio.vizeu@gmail.com

Edson Ronaldo Guarido Filho

Universidade Positivo

edson.guarido@gmail.com

Recebido em: 22/03/2015. Aprovado em: 30/11/2016.

Avaliado pelo sistema double blind review

Avaliador científico: Sabrina Soares Silva

DOI: $10.21714 / 2238-68902016 v 18 n 4 p 342$

\begin{abstract}
This paper makes an overview of the organizational field of waters in Brazil, in order to identify the roots of its peculiarities. We adopted the historiographical review as analytical method, following the efforts of the movement for more history in Organizational Studies. Therefore, the landmarks pointed out in our review were evaluated from the prevailing conception of each season. In this sense, we reveal distinct conceptions of water: as an abunudat and inexhaustible reource, a strategic issue for industrialization, an exclusive resource in charge of Federal Administration, and a good with multiple use and interests..
\end{abstract}

Palavras-chave: Governança das Águas, Revisão Historiográfica, Águas no Brasil.

Keywords: Water Governance, Historiographical Review, Waters in Brazil.

\section{INTRODUÇÃO}

A água, cada vez mais vem sendo considerada uma questão prioritária na agenda do Estado, da sociedade civil e das empresas, tendo em conta a crise ambiental que se estabeleceu no planeta. $\mathrm{O}$ discurso dominante do desenvolvimento sustentável, contraditoriamente centrado nos mesmos interesses que provocaram o colapso ecológico (VIZEU; MENEGHETTI; SEIFERT, 2012), defende que o sistema hídrico deve ser tratado como um mecanismo fundamental para o desenvolvimento econômico dos países capitalistas, e que a preservação deste importante recurso garantirá o bem-estar social e econômico das gerações futuras. Entretanto, ao se tratar a água exclusivamente como recurso econômico, deixase de considerar a sua dimensão ecológica. Assim, sendo o fator condicionante da vida - não somente humana
- deve ser debatida em uma perspectiva mais ampla que a dimensão econômica.

Por outro lado, a complexa rede de significações em torno da água nos remete a questão da construção de um campo organizacional plural e com diferentes interesses, regido por um conjunto de regras que é condicionado por uma mentalidade historicamente constituída. Essa ideia de mentalidade histórica, muito difundida dentro da corrente historiográfica francesa conhecida como escola de Annales (LE GOFF, 1990), é uma abordagem interessante para se pensar na relação entre instituições, organizações e história (VIZEU, 2010). No presente estudo, foi considerado que a mentalidade histórica que suporta o campo organizacional é resultante de práticas e de eventos que são mais bem compreendidas quando situados cultural e historicamente (BOOTH; ROWLINSON, 2006). 
Pretende-se com o presente trabalho rever o percurso histórico de constituição do sistema de regulação do campo organizacional das águas brasileiras, especificamente, no que diz respeito aos órgãos e departamentos do Estado criados para este intento e em como estas mudanças afetaram a construção de um entendimento específico sobre a organização e atividade relacionada aos recursos hídricos no Brasil. Entendemos que a vida social das organizações ocorre em arenas de interesses, ou seja em um campo organizacional, onde os atores levam um ao outro em consideração apresentando uma dinamicidade. No entanto, os campos organizacionais também implicam uma ordem estável, que representa a reprodução dos papéis dos atores e suas posições ao longo do tempo, descrito como um nível meso da ordem social (KLUTTZ; FLIGSTEIN, 2016).

A escolha pelo sistema de regulação se deu por considerar o aspecto regulador como um dos pilares da institucionalização de um campo (DIMAGGIO; POWELL, 2005). Neste sentido, a questão da água no Brasil e os distintos grupos de interesse que envolve é importante pelo fato deste ser o quinto maior país do mundo em extensão territorial e o segundo em tamanho do sistema hídrico, algo recorrentemente mencionado nos fóruns políticos nacionais e internacionais sobre a atual crise da água doce.

A ideia é analisar o percurso histórico de formação deste campo organizacional de maneira a sinalizar como certas premissas postas para legitimar ou justificar maneiras específicas de organização do sistema hídrico refletem, antes, uma mentalidade construída ao longo do processo histórico. Isso nos leva a considerações e questionamentos que podem servir para uma reflexão crítica sobre este campo, ou seja, de que maneira a mentalidade historicamente construída pode revelar aspectos ideológicos e relações de poder que influenciam a percepção da sociedade civil sobre esta matéria.

Neste sentido, o presente trabalho levantou que ocorreu uma mudança sobre a visão da água de um recurso econômico importante para a industrialização e desenvolvimento do Brasil para uma mentalidade de recurso múltiplo que deve levar em conta múltiplos atores interessados. Nessa mudança de mentalidade observou-se a crescente importância da Governança do Estado (COSTA; GUARIDO FILHO; GONÇALVES , 2014), com a criação da Agência Reguladora de Águas.

O conceito de mentalidade adotado pelos historiadores sociais (ARIES, 1990; LE GOFF, 1990), é utilizado aqui como premissa ontológica. Assumimos que cada sociedade constrói historicamente um conjunto de ideias para a justificação de suas ações institucionalizadas, sendo tal mentalidade tomada, por vezes, como a própria realidade percebida (BERGER; LUCKMANN, 1983). Todavia, tal processo histórico se dá na totalidade desta sociedade, pois configura a luta de interesses que se chocam no mundo vivido e que sustentam discursivamente as relações de poder e o sentido coletivamente construído (que, sob uma perspectiva crítica, se configura como a ideologia).

A busca pela reconstrução histórica do campo organizacional da água no Brasil se deu pelo levantamento de documentos e outras literaturas relevantes. Assim, os dados foram obtidos a partir de fontes secundárias de natureza documental. Dos documentos analisados, destacaram-se os estudos feitos ao longo do período de estruturação do campo, bem como as legislações específicas que foram sendo criadas para regulamentar a atividade dos sujeitos interessados. Além disso, a formalização da lei e sua efetivação são observadas tendo em vista o caráter cronológico de desenvolvimento desses aparatos, bem como o contexto histórico mais amplo do Brasil. O objetivo deste esforço foi descrever o sistema de regulação do campo organizacional das águas brasileiras, que é especialmente caracterizado por um modelo de governança baseado em um aparato estatal dedicado especificamente para esta finalidade. Isso implica em descrever como se desenvolveu, o processo de estruturação da governança do Sistema Nacional de Recursos Hídricos do Brasil, considerado a partir da identificação ao longo do período estudado de três importantes elementos relatados pela literatura do institucionalismo organizacional (COSTA; GUARIDO FILHO; GONÇALVES, 2014): a consistência institucional, os modelos de regulação e as práticas de ação política.

Finalmente, o presente trabalho também pretendeu contribuir para o esforço que vem sendo empreendido por pesquisadores no Brasil e no exterior para ampliação na área de estudos organizacionais da perspectiva histórica. Este intento torna-se significativo para uma mudança de olhar cada vez mais necessária sobre as organizações e o conjunto de teorias que tenta explicar este objeto. Conforme sugerem vários autores, o pesquisador das organizações precisa assumir a historicidade deste fenômeno, para que se possa construir um entendimento mais acurado sobre suas especificidades e prover um conhecimento adequado as diferentes realidades e contextos (VIZEU, 2010; VIZEU, 2011; USDIKEN; KIESER, 2004). 
O artigo está organizado em quatro partes. Primeiramente, apresentamos os aspectos metodológicos, após o resultado de nossa revisão documental sobre a trajetória histórica do campo organizacional das águas no Brasil, onde descrevemos o desenvolvimento cronológico da legislação e dos organismos governamentais que indicam a estruturação do campo e de seus atores. Em seguida, apresentamos a discussão dos principais marcos históricos e suas implicações para a formação da mentalidade sobre o sistema hídrico brasileiro, dando subsídios analíticos para inferir sobre o atual cenário ambíguo e complexo do campo das águas no Brasil. Finalmente, apresentamos as considerações finais e recomendações para futuras pesquisas.

\section{MATERIAL E MÉTODOS}

Em se tratando de uma pesquisa historiográfica, nossa investigação empírica teve como desafio levantar informações e dados históricos relevantes para a descrição da trajetória de constituição do campo organizacional dos Recursos Hídricos no Brasil. Sendo assim, o procedimento escolhido foi análise documental e foram levantados tipos de documentos que pudessem caracterizar a história e desenvolvimento do campo organizacional das águas no Brasil.

Tendo por base estudos prévios sobre o tema e entrevistas realizadas com atores relevantes no campo tratadas já em estudo anterior foram identificados três diferentes tipos de fontes documentais relevantes para a presente pesquisa: i) Legislações relacionadas ao tema água e recursos hídricos; ii) documentos oficiais de órgãos e agências reguladoras do campo; e iii) trabalhos acadêmicos (artigos, relatórios de pesquisa, dissertações e teses) realizados. Os primeiros dois tipos foram considerados relevantes para apresentar a existência de regras formais sancionadas na forma de leis ou expressas por padrões normativos que orientam o comportamento dos atores participantes de determinado campo organizacional, por meio da definição de sanções, modos de interação e procedimentos generalizáveis, ligados a programas de desempenho, práticas de gestão e processos organizacionais (SELZNICK, 1969; EDELMAN, SUCHMAN, 1997).

Os documentos oficiais também foram importantes para a verificação de arranjo de atores, papéis e regras que visam ao controle do ambiente legal, seja em relação à sua reformulação, seja quanto aos procedimentos necessários ao cumprimento das leis (JORDANA, LEVI-FAUR, MARIN, 2007).

Já os trabalhos acadêmicos foram selecionados de acordo com a demarcação de eventos históricos relevantes para o campo e possibilidade de identificar ações que influenciaram a criação e/ou alteração da estrutura regulativa normativa do SNRH.

Uma explicação sucinta da natureza destes documentos é apresentada no Quadro 1.

QUADRO 1 - Tipos de Documentos

\begin{tabular}{|c|c|}
\hline TIPO & DESCRIÇÃO \\
\hline Legislação & $\begin{array}{l}\text { Composta pelas Ordenações Filipinas; Código de Águas; Código Civil; Constituições de } \\
\text { 1891, 1934, } 1937 \text { e 1988, além de coletânea de legislação de direito ambiental organizada por } \\
\text { Odete Medaula (2002). }\end{array}$ \\
\hline $\begin{array}{l}\text { Documentos oficiais de órgãos e } \\
\text { agências reguladoras do campo. }\end{array}$ & $\begin{array}{l}\text { Anais do Seminário Internacional de Recursos Hídricos de } 1983 \text { do Departamento Nacional } \\
\text { de Águas e Energia Elétrica da Secretaria Especial do Meio Ambiente e Ministério do } \\
\text { Interior, por ter reunido informações acerca do gerenciamento de recursos hídricos com vistas } \\
\text { a dirigir atenção para pontos de interesse à experiência brasileira. Plano Nacional de Recursos } \\
\text { Hídricos do Ministério do Meio Ambiente do ano de 2006; Programa de Desenvolvimento } \\
\text { de Recursos Hídricos Pró-Água Nacional do ano de } 2007 \text { que visa resgatar o modo como a } \\
\text { água era usada na época do Império e documentos publicados e não publicados da Agência } \\
\text { Nacional de Águas e Ministério do Meio Ambiente e da Amazônia Legal, tratam de relatório } \\
\text { técnico de levantamento e análise dos artigos da Lei n. } 9433 / 97 \text { que foram encomendados } \\
\text { pela UNESCO e Secretaria de Recursos Hídricos e Ambiente Urbano do Ministério do Meio } \\
\text { Ambiente }(2009,2010) \text {. }\end{array}$ \\
\hline $\begin{array}{l}\text { Artigos ou relatórios de } \\
\text { pesquisa que procederam em } \\
\text { revisões históricas sobre eventos } \\
\text { e fatos relevantes para o campo }\end{array}$ & $\begin{array}{l}6 \text { livros que visavam verificar a História do Brasil, dados conjunturais e econômicos, } 04 \\
\text { artigos científicos e } 03 \text { dissertações de mestrado. }\end{array}$ \\
\hline
\end{tabular}

Organizações Rurais \& Agroindustriais, Lavras, v. 18, n. 4, p. 342-355, 2016 
Conforme se observa, com relação aos documentos utilizados, coletaram-se além das legislações, principalmente dados junto a Secretaria de Recursos Hídricos e Mudança Climática (anteriormente denominada Secretaria de Recursos Hídricos e Ambiente Urbano), vinculada ao Ministério do Meio Ambiente, sediada em Brasília, ao Conselho Nacional de Recursos Hídricos (órgão colegiado da estrutura regimental do Ministério do Meio Ambiente, criado pela Lei no 9.433, de 8 de janeiro de 1997, com as alterações da Lei no 9.984, de 17 de julho de 2000, regulamentado pelo Decreto no 4.613, de 11 de março de 2003, que integra o Sistema Nacional de Gerenciamento de Recursos Hídricos, na qualidade de órgão consultivo e deliberativo) e a Agência Nacional de Recursos Hídricos. Foram utilizados também documentos não divulgados em mídia, fornecidos por representantes do Ministério do Meio Ambiente, matérias oriundas da mídia, além de livros, dissertações e teses de pós-graduação stricto-sensu.

A narrativa histórica como método de investigação e análise tem sido utilizada por muitos pesquisadores da área de Estudos Organizacionais. Neste sentido, Vizeu (2010) lembra que esta perspectiva consiste em uma construção textual sobre o passado, baseado em evidências e em outros relatos historiográficos, de forma a constituir uma explicação consistente sobre a trajetória diacrônica de um campo social em específico. Neste ponto, seguimos a perspectiva do historiador Peter Burke, que entende que toda historiografia é uma narrativa, uma versão do passado (BURKE, 1992).

Assumindo essa perspectiva historiográfica, entende-se que o estudo contribui para uma análise organizacional para além do reducionismo histórico ainda presente nos estudos do campo (VIZEU, 2010; BARROS, 2013). Assim, embora possua diversas especificidades, a narrativa histórica assume um papel importante na medida em que permite articular o sujeito (historiador) e seu objeto de pesquisa (os fenômenos históricos) e, a partir disto, formular três estratos de análise de documentos, seguidos nesta pesquisa: o distanciamento objetivador das fontes, a elucidação de sua lógica estrutural interna e a retomada de sentido na hermenêutica do outro (CARNEIRO, 2014).

\section{A TRAJETÓRIA HISTÓRICA DO CAMPO DE RECURSOS HÍDRICOS}

\subsection{O Prelúdio do Campo das Águas: Período Colonial e Século Dezenove}

Dada a adoção da perspectiva histórica, e para melhor contextualizar os dados sobre o campo organizacional das águas, faz-se necessário primeiro pontuar os aspectos que fundamentam os antecedentes históricos sobre o desenvolvimento social, cultural, econômico e político do Brasil. A apreciação desses elementos se deu a partir das menções feitas em documentos do campo, especialmente, em estudos encomendados ou publicados em sites oficiais dos órgãos governamentais e outros ligados ao campo organizacional do sistema hídrico brasileiro.

Considerando o período de formação política deste país - ou seja, o período pré-republicano (HOLANDA, 1995; PRADO JUNIOR, 1971; SKIDMORE, 1999) - a regulamentação específica sobre o uso e direito sobre a água esteve praticamente ausente da pauta governamental. Entretanto, deve ser considerado que, no período colonial, a orientação política do governo português era fortemente direcionada para a exploração dos recursos da colônia americana. Isso não foi diferente em relação ao sistema hídrico, considerado sempre a luz dos interesses de exploração econômica que privilegiavam os cofres da metrópole portuguesa (ANA, 2007). Neste sentido, o pressuposto que permeou a incorporação do Brasil ao sistema econômico mercantilista europeu foi a ideia de ser esse território uma fonte inesgotável de recursos naturais (SKIDMORE, 1999; HOLANDA, 1995) ${ }^{1}$. Por esse motivo, as regras de organização do processo extrativista e de exploração de recursos, além de poucas, não objetivavam a preservação desses bens, mas sim, a garantia dos interesses econômicos dos colonizadores (CANALI, 2009).

Assim sendo, no processo de colonização da América portuguesa, a partir de 1530, Portugal atribuiu à colônia americana a mesma legislação que possuíam as Ordenações Afonsinas, as quais não faziam nenhuma referência às águas nos artigos relacionados às questões ambientais, conforme aponta Franco (2005). De acordo com outro autor, a primeira menção reguladora do meio ambiente deu-se com a submissão de Portugal ao trono espanhol, no período de 1580 a 1640 (ALTAFIN, 2003). Nesse período, passaram a vigorar no Brasil as Ordenações Filipinas, que enfatizam, no parágrafo $7^{\circ}$ do Título LXXXVIII, a proteção das águas a atos de poluição, sendo esta a única menção à matéria nesta legislação.

De fato, de acordo com os documentos que relatam a história da regulamentação ambiental no Brasil, de 1640 a

\footnotetext{
${ }^{1}$ Como bem lembram Bursztyn e Oliveira (1982) em sua análise histórica do sistema hídrico brasileiro, pode-se observar que, já na descoberta do Brasil, Pero Vaz de Caminha, ao descrevê-lo ao Rei Dom Manuel, considerou esse recurso inesgotável em sua quantidade e, ao mesmo tempo, de valor econômico, ao atribuir-Ihe a possibilidade de obter-se de tudo.
} 
1808, a única legislação codificada a considerar os recursos hídricos foram as Ordenações Filipinas (CANALI, 2009). Porém, a partir de 1808 quando o Brasil passou a ser a sede do império português, ocorre a inversão do pacto colonial, e os interesses sobre o território brasileiro deixam de ser exclusivamente de exploração econômica (FAORO, 2001; SKIDMORE, 1999; HOLANDA, 1995). Apesar de nenhuma legislação específica sobre as águas ter sido criada neste período, a chegada da família real em 1808 marcou a consolidação de importantes instituições políticas, sociais e econômicas no país que tornaram a preocupação com o sistema hídrico algo crescente. Alguns eventos históricos são marcantes neste sentido, tais como a abertura dos portos para a mercantilização, a criação de cargos e órgãos públicos que passaram a configurar a estrutura política do país e o livre estabelecimento de fábricas e manufaturas (LUZ, 2004).

Como se almejava em outras colônias americanas da época, desde as Revoluções Americana (1776) e Francesa (1789), o marco de independência era visto como uma conquista à autonomia diante das potências econômicas internacionais (CANALI, 2009). No entanto, no caso da independência do Brasil, a história foi marcada por contradições. A elite agrária, interessada em garantir seus privilégios e em assumir o controle econômico do país no lugar dos portugueses, articulou-se e influenciou decisivamente as instituições no Brasil do século Dezenove. Alguns mecanismos foram importantes para esta articulação, tais como a propagação da ideologia de liberalismo, dificultando o desenvolvimento da indústria nacional e a despeito dos esforços de estímulo a industrialização empreendidos pelo governo imperial (LUZ, 2004); o fortalecimento do sistema social e econômico agro-exportador, baseado especialmente na escravidão e na existência do Poder Moderador (LYNCH, 2005; NEEDELL, 2001). Neste aspecto, a concepção de Poder Moderador foi herdada das ideias da Revolução Francesa, onde a lógica de democracia surgia com a ideia de que o poder do Estado haveria de, prioritariamente, representar a vontade soberana do povo e, a partir daí, definir a distribuição do poder político entre as demais instituições. Todavia, no caso do Brasil imperial, o poder Moderador apresentava-se de forma ambígua e arbitrária, pois se moldava de acordo com os interesses de um estamento político que se adaptava às forças econômicas de cada momento (FAORO, 2001). Conforme aponta Lynch (2005), a ambiguidade jurídico-doutrinária em torno do Poder Moderador se refletiu na Constituição de 1824: por um lado, a primeira Constituição do Império era ultraliberal e considerava que o Imperador era apenas um árbitro do sistema constitucional, por outro, também considerava o princípio do regime monárquico no qual o chefe de Estado era apresentado como o eixo de toda a atividade governamental. Por sua vez, essa dualidade foi responsável pelas tensões que permeavam o cenário e por moldar a política brasileira, tradicionalmente entre um modelo liberal, mas oligárquico, e outro autoritário, mas modernizador (FAORO, 2001).

Assim sendo, foi somente no final do século Dezenove que as pressões para a regulamentação das águas brasileiras tiveram eco no Estado, por conta da estabilidade política que emerge com o surgimento do regime republicano e de sua orientação ideológica de modernização social econômica. Neste ponto, com a emergência da primeira República houve o estabelecimento de uma orientação política de gradual estímulo à industrialização e à urbanização, processos estes que provocaram um significativo crescimento demográfico (SKIDMORE, 1999; LUZ, 2004) e salientaram a preocupação com a questão das águas (BRASIL, 1983; CANALI, 2009).

\subsection{A Industrialização Enquanto Marco Regulatório do Sistema Hídrico Brasileiro}

Bursztyn e Oliveira (1982) consideram que a caracterização do gerenciamento dos recursos hídricos em todo o mundo está diretamente relacionada com ações que passam a ser empreendidas a partir do início da era industrial. Da mesma forma, no Brasil, verifica-se, pela sua história, que é também a partir da industrialização que o aparato regulatório começou a ser considerado necessário. Ou seja, a partir da industrialização brasileira e sua demanda por energia elétrica é que se dão as primeiras iniciativas de aproveitamento do sistema hídrico, observado a partir do seu potencial hidro-energético. Essa concepção das águas como um recurso essencial para a industrialização fez despertar progressivo e amplo interesse na regulamentação e controle de seu uso pelo poder estatal, conforme salienta o relatório da Secretaria de Recursos Hídricos:

Neste contexto, o surgimento da produção de energia elétrica a partir do aproveitamento de potenciais hidro-energéticos é um notório fator de incremento pelo interesse em sistemas legais e institucionais de controle do uso da água que propiciassem maior segurança aos investidores, até então privados, em sua quase totalidade. (SECRETARIA DE RECURSOS HIDRICOS, 2006, p. 54). 
De acordo com essa perspectiva, os primeiros interesses de regulação no Brasil foram consequência da necessidade de proteger os investimentos privados para geração da energia elétrica, garantindo um recurso considerado fundamental para o desenvolvimento da crescente atividade industrial. Em 1889, foi inaugurada, na cidade de Juiz de Fora, Minas Gerais, a usina hidrelétrica de Marmelos, a primeira da América do Sul (LOUREIRO, 2009). No entanto, deve-se considerar que a necessidade de regular a quantidade de água disponível deveu-se também pelos problemas de poluição vivenciados, inundações e secas, melhoria da navegabilidade e captação de água para abastecimento público, caracterizados por Bursztyn e Oliveira (1982) como fatores característicos da primeira fase de gerenciamento de recursos hídricos.

Desse conjunto de fatores, outro de grande impacto para o processo de industrialização foi a questão das vias pluviais. Realmente, considerando a enorme malha pluvial do Brasil, os rios têm sido um importante meio de transporte de pessoas e mercadorias, desde os tempos coloniais. Entretanto, com a modernização econômica, esta questão torna-se estratégica para o Estado. Isso pode ser evidenciado já na Constituição de 1891, que atribui o direito de a União e de os Estados legislarem sobre a navegação interior e estabelece a competência ao Congresso Nacional para legislar sobre a navegabilidade de rios:

Art 13 - O direito da União e dos Estados de legislarem sobre a viação férrea e navegação interior será regulado por lei federal. (...)

Art 34 - Compete privativamente ao Congresso Nacional: (...)

$6^{\circ}$ ) legislar sobre a navegação dos rios que banhem mais de um Estado, ou se estendam a territórios estrangeiros (Constituição Federal, 1891).

Observa-se que a Constituição de 1891 ateve-se apenas à definição de competências legislativas sobre as águas, como é mencionado no Artigo 34, intencionando normatizar a garantia de propriedade incidente sobre esse recurso natural. Por outro lado, problemas sociais que passaram a preocupar o Estado brasileiro republicano começaram a ser considerados no início do século Vinte como indutores de articulação política em torno da questão do sistema hídrico.

Os problemas sociais relacionados às águas também foram considerados nestes primeiros esforços de regulamentação do sistema hídrico brasileiro. Neste ponto, Silva (2004) afirma que a seca no Nordeste brasileiro foi responsável pela criação, em 1904, da Comissão de Açudes e de Irrigação, primeira comissão com vistas à gestão pública da água. Embora, no Império, tenha surgido o interesse pela gestão da água com a formação da Comissão Imperial para estudar a abertura de um canal que comunicasse as águas do rio Jaguaribe com as do rio São Francisco, a prioridade foi dada à construção de açudes e poços tubulares, ainda que a abertura do canal não tenha se concretizado. Foi somente no ano de 1904 que a preocupação com a seca se concretizou em ações diretas do Estado, por meio da criação de várias comissões: Açudes e Irrigação, Estudos e Obras contra os Efeitos das Secas e de Perfuração de Poços (PASSADOR; PASSADOR, 2010). No início do século $X X$ o problema das secas no Nordeste torna-se mais grave (SKIDMORE, 1999), fato este que mobilizou o Estado para a criação de organizações específicas para este fim. Assim, em 1909, foi instituída a Inspetoria de Obras Contra as Secas (IOCS), transformada, em 1919, em Inspetoria Federal de Obras Contra as Secas (IFOCS) (PASSADOR; PASSADOR, 2010).

\subsection{A Emergência do Código das Águas}

Naquele mesmo ano de 1904, foi proposto o Código de Águas ao Congresso Nacional, como resultado dos estudos para a regulamentação dessa matéria (CANALI, 2009; CAROLO, 2007). Porém a iniciativa foi fracassada, e a regulamentação do sistema hídrico brasileiro somente foi concretizada com o estabelecimento do Código Civil de 1916. Observa-se que, no Código Civil, as águas são consideradas como um bem privado e o único artigo relacionado a esta matéria apenas se referia a questões do direito de vizinhança, respeitando-se o direito de navegação ${ }^{2}$.

Nesse contexto histórico, em âmbito mundial, no período de 1919-1923, a tendência dos países mais desenvolvidos como os Estados Unidos, Itália e França foi voltar-se para a expansão da indústria hidrelétrica, para atender à demanda por energia causada em decorrência da expansão industrial. Em complemento, em razão do interesse de vários Estados nacionais na utilização de rios internacionais, foi firmada, em 1923, uma Convenção em Genebra, visando normatizar a instalação de forças hidráulicas, conforme afirma Carolo (2007). Por outro lado, a crise da Bolsa de Nova York, em 1929, e a consequente propagação da lógica do Estado de Welfare,

${ }^{2}$ Art. 540. Quando o terreno aluvial se formar em frente a prédios de proprietários diferentes, dividir-se-á entre eles, na proporção da testada de cada um sobre a antiga margem; respeitadas as disposições concernentes à navegação. (Código Civil Brasileiro, 1916). 
foi responsável pela disseminação da ideia de intervenção do Estado na economia, princípio que também afetou a regulamentação das águas.

No Brasil, a crise econômica internacional impactou diretamente nas oligarquias e foi mais um motivo para conflito de interesse entre as diferentes elites que disputavam no cenário político nacional (PRADO JUNIOR, 1971). O então presidente paulista, Washington Luís, resolveu apoiar a candidatura de seu conterrâneo Júlio Prestes, rompendo o arranjo que vigorava no Brasil, conhecido como "Política do Café com Leite", em que os latifundiários mineiros e paulistas se alternavam no mandato presidencial. Insatisfeitos com tal medida, um grupo de oligarquias dissidentes - principalmente dos Estados de Minas Gerais, Rio Grande do Sul e Paraíba - criaram uma chapa eleitoral contra a candidatura de Júlio Prestes.

Encabeçada por Getulio Vargas, essa chapa eleitoral, denominada Aliança Liberal, prometia um conjunto de medidas reformistas e defendia a instituição do voto secreto, o estabelecimento de uma legislação trabalhista e o desenvolvimento da indústria nacional (PRADO JUNIOR, 1971; FAUSTO, 2001; SKIDMORE, 1999; IANNI, 1986). Embora o candidato paulista Júlio Prestes tenha sido considerado vencedor das eleições daquele ano, o assassinato de João Pessoa, em 26 de julho de 1930, importante componente da chapa liberal, desencadeou a articulação dos liberais e de certo grupo de militares, objetivando a derrubada do governo oligárquico. Esse movimento, conhecido como o 'Golpe de 1930', resultou no impedimento da posse do presidente eleito, Júlio Prestes, em 24 de outubro de 1930. Depois de controlar os focos de resistência nos Estados, Getulio Vargas e seus aliados chegaram ao Rio de Janeiro, em novembro de 1930. Essa revolução pôs fim à República Velha e deu início à chamada Era Vargas, por meio do Governo Provisório. Getúlio Vargas permaneceu por quinze anos ininterruptos no poder, no período de 1930 a 1945. (PRADO JUNIOR, 1971; FAUSTO, 2001; SKIDMORE, 1999; IANNI, 1986).

Com a criação da Subcomissão de Minas, em 1933 e sob a influência do conturbado cenário político das décadas de 1920 e 1930 que instituiu o governo de Vargas, em 10 de julho de 1934 foi editado o Decreto-lei no 24.643, que instituiu o Código das Águas com reformulações relativas à produção de energia elétrica, procurando atender às demandas de um País que se urbanizava (BRASIL, 2011; SILVESTRE, 2008). Em 16 de julho do mesmo ano, foi promulgada a Constituição pelo governo de Vargas, inaugurando o Estado social brasileiro, influenciado pela lógica do contexto mundial do Estado de Welfare (FAUSTO, 2001; IANNI, 1986). Este modelo de Estado, de caráter marcadamente intervencionista, assumiu o controle do crédito, da moeda e do câmbio para conter a inflação; criou leis tributárias de incentivo à iniciativa empresarial; principiou uma interferência no contrato de trabalho e caracterizou-se pela concentração do poder nas organizações públicas, algumas das quais aprovavam concessões e autorizações de uso da água, consagrando, assim, o modelo burocrático de gestão dos recursos hídricos. (CANALI, 2009; IANNI, 1986). E essas características estão presentes no código de Águas, como sugere Silvestre (2008, p. 2):

O Código de Águas foi parte de um conjunto de iniciativas que, desde o início da 'Era Vargas', atingiu os mais variados aspectos da vida brasileira. Com a chamada Revolução de 30, finalmente começa a se concretizar um ideal acalentado desde a segunda metade do século XIX por importantes personalidades do movimento republicano: fazer do Brasil um país moderno, industrializado, desenvolvido. (SILVESTRE, 2008, p. 2).

Ou seja, nesta codificação específica para o sistema hídrico, há uma guinada significativa em relação à legislação anterior. Enquanto o Código Civil de 1916 regulamentava as águas tendo como fundamento o direito de vizinhança e que a utilização das águas deveria ser questão de caráter privado e de valor inexpressivo face à sua abundância, o Código de Águas passou a considerá-la um dos elementos básicos do projeto de desenvolvimento social e econômico do Brasil.

Assim, composto por três "Livros" - águas em geral e sua propriedade (Livro I), aproveitamento das águas (Livro II) e forças hidráulicas, regulamentação da indústria hidrelétrica (Livro III), o Código de Águas (BRASIL, 2011) introduziu a proibição à derivação das águas públicas para aplicação na agricultura, indústria e higiene, sem a existência de concessão, no caso de utilidade pública, e de autorização nos outros casos. Porém, em qualquer hipótese, dava preferência à derivação para abastecimento às populações. Além disso, essa regulamentação estabeleceu que a concessão ou a autorização deveria ser feita sem prejuízo da navegação, salvo nos casos de uso para as primeiras necessidades da vida ou previstos em leis especiais.

O Código de Águas também inovou no que se refere à política pública das águas vigente em outros países industrializados (MACHADO, 2002): estabeleceu mecanismos de intervenção governamental com vistas a garantir a qualidade e a salubridade dos recursos hídricos. 
Este dispunha que a ninguém era lícito conspurcar ou contaminar as águas que não consumisse, com prejuízo a terceiros e ressaltava que os trabalhos para a salubridade seriam executados à custa dos infratores, conforme é observado nos Artigos 109 e 110.

Considerando o desenvolvimento do campo organizacional das águas no Brasil, este código foi a primeira legislação a retratar as águas como recursos dotados de valor econômico para a coletividade e, por isso, merecedores de atenção especial do Estado. Confirmando o intervencionismo estatal, o Código de Águas restringiu o domínio privado, ampliando o domínio estatal sobre as águas, dividindo-as em três categorias básicas, a saber: as públicas; as comuns; e as privadas. As águas públicas foram ainda subdivididas em: de uso comum; e dominicais. Sendo águas públicas dominicais todas aquelas situadas em terrenos que ostentassem a condição de domínio público dominical, quando não fossem do domínio público de uso comum, ou não fossem comuns.

O Código de Águas estabeleceu ainda, em conformidade com disposições constitucionais, que a propriedade das minas e demais riquezas do subsolo passariam a constituir propriedade distinta da propriedade do solo, estabelecendo-se que as quedas de água e outras fontes de energia hidráulica seriam consideradas bens imóveis, tidas como coisas distintas e não integrantes das terras em que se encontrassem. A propriedade superficial não mais abrangeria nem a água em si mesma, nem o álveo do curso no trecho em que se achasse a queda de água, nem a respectiva energia hidráulica, para efeito de seu aproveitamento.

Diante de tal regulamentação, inovando aquela que tratava a água como um bem essencialmente privado, coube ao Código de Águas e à Constituição de 1934 disporem de forma clara sobre os aspectos econômicos ligados ao sistema hídrico brasileiro. De fato, o Código de Águas se constituía como espinha dorsal do arcabouço legal vigente, tido como de qualidade ímpar e avançado para o seu tempo (SILVESTRE, 2008). Todavia, sua implementação não se deu conforme era esperado, mesmo considerando que levou cerca de trinta anos em gestação e tramitação até sua edição, em 1934. Um dos fatores do insucesso foi precisamente a omissão quanto ao sistema de gerenciamento das águas. Nesse particular, a complexidade era maior, uma vez que esta codificação não restringia o domínio das águas ao âmbito da União e dos Estados, admitindo o domínio municipal e, ainda, o domínio privado, em determinadas circunstâncias.
Era de se prever imensas dificuldades em sua implementação, frente à divisão de competências na Federação, ainda jovem, e à carência de informações necessárias ao gerenciamento, bem como consideradas a imensidão do território nacional e a complexidade dos seus sistemas hídricos, agravada pela interpenetração dos domínios, portanto, da gestão pública, em todas as diferentes instâncias. Além disso, nos Estados federativos, o desenvolvimento institucional e econômico se deu de modo desigual (IANNI, 1986). Este fato inviabilizou qualquer configuração sistêmica entre os entes federados para o gerenciamento das águas nacionais. Em adição a este desenvolvimento desigual do aparato organizacional para o sistema hídrico nacional, tem-se o fato de que a União detinha o poder concedente da exploração da energia elétrica, condição que propiciou maior desenvolvimento institucional da União para o gerenciamento das águas, com viés marcadamente setorial e centralizador.

No novo golpe de Vargas e o estabelecimento de um novo regime ditatorial em 1937, o intervencionismo estatal se reforçou ainda mais. Neste sentido, a Constituição Federal de 1937, em relação à tutela dos recursos hídricos, repetiu os preceitos de sua antecessora, porém acrescentou, como competência privativa da União, a autorização para uso das águas, sendo consideradas - assim como as jazidas minerais bens separados da propriedade da terra, como pode ser observado no texto da Carta Magna:

Art. 143 - As minas e demais riquezas do subsolo, bem como as quedas d'água, constituem propriedade distinta da propriedade do solo para o efeito de exploração ou aproveitamento industrial. $\mathrm{O}$ aproveitamento industrial das minas e das jazidas minerais, das águas e da energia hidráulica, ainda que de propriedade privada, depende de autorização federal.

Inovou essa Constituição, ao criar um capítulo específico reservado à ordem econômica, sendo reconhecido o papel essencial dos recursos hídricos no desenvolvimento econômico. Mesmo com o fim da ditadura de Vargas e a outorga de uma nova Constituição Federal em 1946, a orientação intervencionista da União na matéria das águas permaneceu, se mantendo a competência privativa da União para legislar sobre as águas e deixando para a legislação estadual competência supletiva ou complementar. Apesar deste aparato regulatório, a estrutura organizacional do campo das águas ainda carecia de um sistema de gestão mais efetivo, que somente se estabeleceu nos governos seguintes a era Vargas. 


\subsection{A Ampliação dos Atores do Campo das Águas Durante a Década de 1970}

Já em meados do século XX, com o segundo esforço de industrialização articulado com o governo Kubitschek, a questão da regulação das águas manteve-se na pauta constitucional. Todavia, a Constituição Federal de 1967 ainda não dispunha sobre mecanismos de conservação e preservação dos recursos hídricos, refletindo a mentalidade do período colonial de que a água era um recurso renovável, portanto, infinito.

Assim, até a década de 1970, pouco mudou o panorama relativo à gestão das águas, especialmente em relação a outros usos que não o da produção de energia elétrica. Isso é notório com o surgimento da primeira organização formal no governo destinada exclusivamente para o sistema hídrico. Assim sendo, em dezembro de 1965, a Lei $\mathrm{n}^{\circ} 4.904$ instituiu o Departamento Nacional de Águas e Energia (DNAE), órgão vinculado ao Ministério das Minas e Energia. Esse departamento absorveu as responsabilidades da Divisão de Águas do Departamento da Produção Mineral, que pertencia antigamente ao Ministério da Agricultura, bem como do Conselho Nacional de Águas e Energia Elétrica (BRASIL, 1983). A criação deste novo departamento consolidava, nesse período, a predominância do setor de energia elétrica na gestão das águas, e era reforçado pela política desenvolvimentista do regime militar. Por conta desta orientação, em 11 de dezembro de 1968, o Decreto $\mathrm{n}^{\circ} 63.951$ alterou a denominação do DNAE, que passou a ser Departamento Nacional de Águas e Energia Elétrica (DNAEE).

Embora o DNAEE tenha sido criado sob a tutela dos interesses do setor de energia elétrica, ele detinha amplos poderes de fiscalização e cumprimento da legislação de águas. Assim, este departamento tinha a responsabilidade pelo planejamento, coordenação e execução de estudos hidrológicos, bem como pela supervisão, fiscalização e controle dos aproveitamentos das águas, sendo responsável ainda por cumprir e fazer cumprir o Código de Águas e a legislação específica, relativa à água e à eletricidade (BRASIL, 1983).

Em paralelo à criação do DNAEE, inicia-se no regime militar um processo de ampliação dos atores envolvidos no campo das águas. Deste modo, no fim da década de 1960, o Decreto-lei n 200/67 atribuiu a vários Ministérios diferentes atividades relacionadas à gestão de Recursos Hídricos. No plano jurídico, problemas pelos esgotos do rio Tietê faz emergir, em São Paulo, a revisão do Código de Águas, por conta de conflitos no uso múltiplo das águas. Conforme já foi mencionado, o Código de Águas foi regulamentado exclusivamente nos capítulos referentes ao aproveitamento hidrelétrico, sem que se regulamentassem os usos múltiplos e a conservação da qualidade das águas que nele estavam previstas (BARTH, 1999). Para rever e atualizar o Código de Águas, foi criada uma comissão Especial em 1968, particularmente com o objetivo da consideração do aproveitamento múltiplo de bacias hidrográficas (POMPEU, 2006).

Adicionalmente a esse esforço, dados do Ministério do Meio Ambiente relatam que, na década de 1970, a degradação dos recursos hídricos pelos dejetos urbanos e industriais começou a preocupar a sociedade civil e governantes. Assim, em 1973, foi criada a Secretaria Especial do Meio Ambiente (SEMA) do Governo Federal, vinculada ao Ministério de Estado do Interior (MINTER), iniciando o seu funcionamento no início de 1974. O MINTER era responsável pelo planejamento, coordenação e normalização das ações referentes à conservação ambiental e ao controle da poluição em todo o território nacional.

No ano de 1975, a criação do Ministério das Minas e Energia, dada por meio do Decreto $\mathrm{n}^{\circ} 75.468$, teve por consequência a atribuição ao DNAEE a competência, na qualidade de órgão nacional de gestão de recursos hídricos federais, quanto à direção, ao planejamento, à coordenação e à execução de estudos hidrológicos, além dos estudos na área de eletricidade.

Em 1976, em razão dos recorrentes problemas com os rios da região metropolitana de São Paulo, o governo paulista e o Ministério de Minas e Energia firmaram um acordo para uma ação conjunta que solucionasse tal questão. Assim, foi proposta a criação do Comitê Especial de Estudos Integrados de Bacias Hidrográficas (CEEIBH), para promover o uso racional das águas dos rios de domínio da União, com a integração de estudos das diversas organizações que interferissem direta ou indiretamente no uso (SOARES; THEODORO; JACOBI, 2008). Mesmo assim, Braga e Galizia (2006, p. 643) afirmam que as ações realizadas após o Código de Águas objetivaram atender demandas "exclusivamente setoriais e nunca foram regulamentados, por exemplo, os artigos que se referiam ao uso múltiplo e à conservação da qualidade da água". Por esses e outros motivos, o Comitê Especial de Estudos Integrados de Bacias Hidrográficas, cuja criação foi planejada em 1976, foi considerado importante marco por reunir representantes de entidades vinculadas às bacias, tendo em vista garantir o aproveitamento múltiplo dos rios federais e a minimização de consequências nocivas ao meio ambiente. 
Em síntese, observa-se por esse panorama que, embora o Código de Águas tenha sido um importante marco jurídico e tenha permitido expansão do sistema hidrelétrico brasileiro, o período de 1934 a 1976 foi marcado por ações que visaram à resolução de problemas pontuais; convém ressaltar que nunca se realizou a efetiva implementação desse Código. O Quadro 2 apresenta o histórico das legislações, dando uma visão geral do desenvolvimento dos significados construídos em torno do sistema hídrico brasileiro. Na seção seguinte, trataremos da análise destes diferentes significados.

\section{DISCUSSÃO}

No geral, os dados históricos revelam que, desde seu embrionário desenvolvimento, o sistema hídrico brasileiro acompanha a trajetória política do país, refletindo, em sua formação, a conturbada e complexa rede de interesses que circundaram os governos que se sucederam desde o período pré-republicano.

Considerando as peculiaridades do sistema hídrico, tais como, a extensão territorial e a diversidade das regiões, o atual grande número de atores com multiplicidade de interesses que circundam a gestão do campo organizacional das águas no Brasil não se explica sem que se considere a conturbada trajetória história de consolidação do Estado brasileiro (IANNI, 1986; PRADO JUNIOR, 1971). Neste sentido, ressalta-se o lento e gradual processo de regulamentação, quase sempre, associado às necessidades contingentes e problemas que emergiam na medida que o país se desenvolvia social e economicamente.

Diante deste cenário, importante notar a tradição política do país de apropriar-se das questões públicas para atender aos interesses oligárquicos das elites econômicas (FAORO, 2001; PRADO JR., 1971). Este traço foi marcante na construção do campo organizacional das águas, que, desde a sua origem, é fortemente controlado pelo governo federal. Realmente, com o advento da República e a prevalência dos interesses pela modernização econômica e urbana do país, a União assume gradualmente o papel de monopolizador do controle pelo uso da água. Assim, em contraposição ao desinteresse dos governos no período pré-republicano pela regulamentação do uso das águas, é na Primeira República que se articulam os primeiros esforços de formação do campo, onde o Estado estava imbuído dos ideais de modernização e tinha optado pela matriz energética hidrelétrica como impulsionadora do surto industrial no país (SUZIGAN, 2000).

Com a era Vargas, vemos a questão das águas ainda sendo observada como um aspecto associado ao desenvolvimento industrial. Por isso mesmo, o governo atua de forma a tornar ainda mais centralizador e unilateral controle por parte da União. Mesmo assim, a organização do campo das águas ainda se dá somente sob o ponto de vista de marco regulatório, não existindo uma estrutura de fiscalização e controle específica para esta questão.

É somente com o segundo ímpeto pela industrialização e com o novo regime ditatorial instalado

QUADRO 2 - Histórico das Legislações no Brasil Relacionadas às Águas

\begin{tabular}{|c|c|c|}
\hline Ano & Legislação & Descrição \\
\hline $1640-1808$ & Ordenações Filipinas & Enfatizam, no parágrafo $7^{\circ}$ do Título LXXXVIII, a proteção das águas a atos de poluição. \\
\hline 1891 & Constituição Federal & $\begin{array}{r}\text { Competências legislativas sobre as águas, mencionado no artigo 34, intencionando } \\
\text { normatizar a garantia de propriedade incidente sobre esse recurso natural. Não disciplinou } \\
\text { o domínio hídrico. }\end{array}$ \\
\hline 1916 & Código Civil & $\begin{array}{c}\text { Recursos hídricos são considerados como um bem privado, mencionado no artigo 540, } \\
\text { refere-se a questões do direito de vizinhança, respeitando-se o direito de navegação. }\end{array}$ \\
\hline 1934 & Código das Águas & $\begin{array}{c}\text { Considera as águas um dos elementos básicos do desenvolvimento, uma vez que a } \\
\text { eletricidade é vista como produto essencial para a industrialização. Declarou de domínio } \\
\text { da União os lagos e quaisquer correntes em seu domínio, enquanto aos Estados Federados } \\
\text { ficaram com a responsabilidade de conferidos os bens de propriedade desses, bem como as } \\
\text { margens dos rios e lagos navegáveis. }\end{array}$ \\
\hline 1937 & Constituição Federal & $\begin{array}{c}\text { Procura disciplinar a propriedade e o uso das águas, considerando os aspectos econômicos } \\
\text { nele inclusos, por exemplo, os artigos 50, 20 e 118, repetindo as disposições da de 1934. }\end{array}$ \\
\hline $1946 / 1947$ & Constituição Federal & Mantém preocupações de 1937 - água vista como recurso renovável. \\
\hline 1965 & Lei no 4.904 & Institui o Departamento Nacional de Águas e Energia (DNAE). \\
\hline
\end{tabular}

Fonte: Dados de Pesquisa 
pelo golpe militar de 1964 que os múltiplos atores do campo organizacional do sistema hídrico brasileiro começam a se consolidar. Finalmente, na década de 1970, os problemas de urbanização e poluição de rios e lagos condicionam a participação mais plural de atores governamentais de outras instâncias que não somente a Federal. É neste momento que vemos o estabelecimento de múltiplos interesses e atores em torno da questão da água, o que deu ensejo a incorporação do órgão de gestão do sistema hídrico brasileiro ao Ministério do Meio Ambiente, no início da década de 1980 (ANA, 2007; TUCCI; HESPANHOL; CORDEIRO NETTO, 2001).

Partindo da premissa de que cada época apresenta uma peculiar visão de mundo (ARIES, 1990), consideramos que a trajetória do campo organizacional das águas no Brasil apresenta algo que vai além das diferentes regulamentações que se sucederam. Antes, este desenvolvimento regulatório representa diferentes interesses que se consolidam a partir da concepção da época sobre o que é a água. É assim que construímos o Quadro 3, representando estas diferentes significações a partir dos marcos históricos considerados nas seções anteriores.

QUADRO 3 - Múltiplas Significações da Água nos Diferentes Períodos Históricos

\begin{tabular}{|c|c|}
\hline Período histórico & Significado \\
\hline $\begin{array}{c}\text { Período Colonial/ } \\
\text { imperial }\end{array}$ & $\begin{array}{c}\text { Água observada como recurso } \\
\text { abundante, de fontes inesgotáveis, sem } \\
\text { necessidade de maior preocupação por } \\
\text { parte do Estado. }\end{array}$ \\
\hline $\begin{array}{c}\text { Primeira } \\
\text { República }\end{array}$ & $\begin{array}{c}\text { As águas são tomadas em seu potencial } \\
\text { hidrelétrico, entendido como o motor } \\
\text { para a industrialização do país. }\end{array}$ \\
\hline Era Vargas & $\begin{array}{c}\text { As águas são um bem da União. Esta, } \\
\text { por sua vez, detém o poder de regular e } \\
\text { controlar este recurso valioso, garantindo } \\
\text { o desenvolvimento sócio-econômico do } \\
\text { Brasil. }\end{array}$ \\
\hline $\begin{array}{c}\text { Regime Militar } \\
\text { de 1964 }\end{array}$ & $\begin{array}{c}\text { A aceleração do crescimento econômico } \\
\text { e a necessidade pelo desenvolvimento de } \\
\text { infra-estrutura no país, tornam o sistema } \\
\text { hídrico complexo demais para ser } \\
\text { controlado de forma centralizada. Assim, } \\
\text { a água é observada em seus múltiplos } \\
\text { usos, sendo a questão ecológica um dos } \\
\text { aspectos a ser considerados na gestão } \\
\text { deste importante recurso. }\end{array}$ \\
\hline
\end{tabular}

Fonte: Os autores
O Quadro 3 apresenta, de forma ensaística, uma possível interpretação das significações que foram se constituindo ao longo de importantes períodos da história política do país. Vale ressaltar que destacamos apenas os marcos históricos que inauguraram um período de significativas mudanças no sistema hídrico. Entretanto, não significa dizer que este campo permaneceu inalterado desde o período do regime militar; apenas tivemos como corte analítico o momento que se inaugura a atual estrutura de governança do campo. Deve ser considerado como um limite do presente trabalho a delimitação do escopo temporal até este período.

\section{CONSIDERAÇÕES FINAIS}

O presente trabalho vislumbrou tecer um panorama do campo organizacional das águas no Brasil, de maneira a identificar as raízes de suas peculiaridades e ambiguidades. Para tanto, adotou-se a revisão historiográfica como método analítico, seguindo o esforço do movimento por mais história nos Estudos Organizacionais (VIZEU, 2010; ÜSDIKEN; KIESER, 2004).

Ao proceder na revisão histórica sobre a formação do campo organizacional das águas, buscou-se ter por inspiração analítica o conceito de mentalidade (LE GOFF, 1990; ARIES, 1990). Entretanto, ressaltamos que a ideia de mentalidade foi tomada aqui de forma um pouco diversa do movimento francês, que atribuía este conceito a concepção de mundo de toda uma época. Não sendo correto admitir que o recorte temporal que empreendemos represente distintas eras históricas - representadas na escola histórica dos Annales pelo conceito de 'tempo de longa duração' (LE GOFF, 1990) - vemos como inspiração na mentalité francesa a questão da ideia predominante de um determinado período histórico na concepção da questão da água e da consequente estruturação governança em torno deste tema.

Assim, os marcos históricos apontados em nossa revisão da historiografia da legislação e dos órgãos de regulamentação e gestão do campo das águas brasileiras foram avaliados a partir da concepção predominante de cada época. Neste sentido, construímos o quadro 3 que revela diferentes concepções, indo da ideia de que a água é um recurso abundante e inesgotável, uma questão estratégica para a industrialização, um recurso de controle exclusivo da União, uma questão de múltiplos usos e interesses, inclusive, relativos a questão ecológica. Interessante notar que esta última afirmação, apesar de parecer irônica, revela, antes, o lugar que o interesse ambientalista assume

Organizações Rurais \& Agroindustriais, Lavras, v. 18, n. 4, p. 342-355, 2016 
na complexa rede de interesses em torno do sistema hídrico brasileiro. Salienta-se, assim, que, mesmo diante das pressões internacionais pela consideração do problema ecológico em torno da água (PNUD, 2006; UNESCO, 2006), ainda se faz predominante o interesse econômico e desenvolvimentista do país, ponto que tem gerado dificuldades para o aperfeiçoamento do sistema de gestão das águas (ANA, 2007).

Finalmente, nosso esforço na adoção da perspectiva histórica revela o potencial analítico deste tipo de estudo para a área de Estudos Organizacionais e da Administração. Apesar de ainda incipiente para uma análise definitiva para o campo organizacional das águas, nosso trabalho pretendeu salientar como é possível assumir tal perspectiva. No caso dos estudos organizacionais brasileiros, acreditamos que este esforço pode sinalizar novas possibilidades para o debate sobre a historicidade do fenômeno organizacional, que deve ser tomado considerando a totalidade do fenômeno histórico (LE GOFF, 1990).

\section{REFERÊNCIAS}

ANA - Agência Nacional de Água. GEO Brasil recursos hídricos: componente da série de relatórios sobre o estado e perspectivas do meio ambiente no Brasil: resumo executivo. Brasília: 2007.

ALTAFIN, I. Sustentabilidade, políticas públicas e agricultura familiar: uma apreciação sobre a trajetória brasileira. Brasília: Universidade de Brasília, 2003.

ARIES, P. A história das mentalidades. In: LE GOFF, Jacques. A História Nova. São Paulo: Martins Fontes, 1990.

BARTH, F. T. Aspectos institucionais do gerenciamento de recursos hídricos. In: REBOUÇAS, A.; BRAGA, B.; J. G. TUNDISI, J. G. (eds.). Águas doces no Brasil: capital ecológico, uso e conservação. 3. Ed., 1999, p. 565-599.

BARROS, A. N. de. Uma narrativa sobre a história dos cursos de adminstração da FACE- UFMG: às margens do mundo e à sombra da FGV?. Tese (Doutorado em Administração). UFMG. 2013.

BERGER, P. L.; LUCKMANN, T. A construção social da realidade: tratado de sociologia do conhecimento 5 . ed. Petrópolis: Vozes. 1983.
BOOTH, C; ROWLINSON, M. Management and organizational history: prospects. Management \& Organizational History, v. 1, n. 1, p. 5-30, 2006.

BRAGA, B.; GALIZIA, J. Águas doces no Brasil: capital ecológico, uso e conservação 3. ed. São Paulo: Escrituras, 2006.

BRASIL. Ministério das Minas e Energia. Seminário Internacional de Gestão de Recursos Hídricos: Anais. (2 vol.). Brasília: DNAEE, 1983. s p.

BRASIL. Decreto 24.643 de 1934. (Código de Águas). Disponível em: http://www.planalto.gov.br. Acesso em 19.11.2011.

BURSZTYN, M. A.; OLIVEIRA, S. Análise da experiência estrangeira no gerenciamento dos recursos hídricos. Ministério do Interior, Secretaria Especial do Meio Ambiente, p. 52-88. 1982.

BURKE, P. A escrita da história. São Paulo: Editora Unesp, 1992.

CANALI, G. V. A Versão Preliminar: Levantamento e análise dos artigos da Lei $n^{\circ}$ 9.433/97. Brasília: Unesco e Secretaria de Recursos Hídricos e Ambiente Urbano, Ministério do Meio Ambiente, 2009.

CARNEIRO, T. A. A narrativa histórica em Estudos Organizacionais: esboço metodológico para análise das organizações. II CONGRESSO BRASILEIRO DE ESTUDOS ORGANIZACIONAIS. Uberlândia, 19 a 21 de novembro de 2014.

CAROLO, F. Outorga de direito de uso de recursos hídricos: Instrumento para o desenvolvimento sustentável? Estudo das bacias dos rios Piracicaba, Capivari e Jundiaí. Dissertação de Mestrado em Desenvolvimento Sustentável, área de concentração Políticas Públicas e Gestão Ambiental. Brasília: UnB, 2007.

COSTA, M. C.; GUARIDO FILHO, E. R.; GONÇALVES, S. A. Lógicas institucionais e formação da governança de recursos hídricos: análise do caso brasileiro. Revista Gestão Organizacional, v. 6, n. 4, p. 99-119, 2013.

DIMAGGIO, P. J.; POWELL, W. W. A gaiola de ferro revisitada: isomorfismo institucional e racionalidade coletiva nos campos organizacionais. Revista de Administração de Empresas, 45(2), 74-89, 2005. 
EDELMAN, L. B., \& SUCHMAN, M. C. THE LEGAL ENVIRONMENTS OF ORGANIZATIONS. ANNUAL REVIEW OF SOCIOLOGY, 23, 479-515, 1997.

FAORO, R. Os donos do poder. 3 . ed. São Paulo: Globo. 2001.

FAUSTO, Boris. História do Brasil. 9. ed. São Paulo: Editora da USP, 2001.

FRANCO, C. A. O Município e a questão socioambiental, bases jurídicas para uma gestão local sustentável. Dissertação de Mestrado em Direito Econômico e Social PUC - PR. 2005.

HOLANDA, S. B. Raízes do Brasil. 26. ed. São Paulo: Companhia das Letras. 1995.

IANNI, O. Estado e Planejamento Econômico no Brasil. 4. ed. Rio de Janeiro: Civilização Brasileira. 1986.

KLUTTZ, Daniel N.; FLIGSTEIN, Neil. Varieties of Sociological Field Theory. In: Handbook of Contemporary Sociological Theory. Springer International Publishing, 2016. p. 185-204.

JORDANA, J., D. LEVI-FAUR; FERNANDEZ I. MARIN. The Global Diffusion of Regulatory Agencies: Institutional Emulation and the Restructuring of Modern Bureaucracy. in IV ECPR General Conference. Pisa, 2007.

LE GOFF, Jacques. A História Nova. São Paulo: Martins Fontes, 1990.

LOUREIRO, P. Custo marginal do déficit de energia elétrica: histórico, avaliação e proposta de uma nova metodologia. Dissertação de mestrado em ciências em planejamento energético. Rio de Janeiro, Brasil: Programa de Pós-graduação em Planejamento Energético, Universidade Federal do Rio de Janeiro. 2009.

LUZ, N. V. A luta pela industrialização no Brasil. 3. ed. São Paulo: Alfa-Omega, 2004.

LYNCH, C. E. O discurso político monarquiano e a recepção do conceito de poder Moderador no Brasil (18221824). Dados, vol. 48, n. 3, p. 611-654, 2005.

MACHADO, P. A. Recursos Hídricos: Direito Brasileiro e internacional (9 ed.). São Paulo: Malheiros. 2002.
NEEDELL, J. Provincial origins of the brazilian state: Rio de Janeiro, the monarchy, and national political organization. Latin American Research Review, vol. 36, n. 3, p. 132-153, 2001.

PASSADOR, C. S.; PASSADOR, J. L. Apontamentos sobre as políticas públicas de combate a seca no Brasil: Cisternas e cidadania. Cadernos Gestão Pública e Cidadania, vol. 15, n. 56, p. 65-86, 2010.

POMPEU, C. T. Direito de águas no Brasil. São Paulo: Ed. Revista dos Tribunais, 2006.

PNUD - Programa das Nações Unidas para o Desenvolvimento. Relatório do Desenvolvimento Humano. A água para lá da escassez: poder, pobreza e a crise mundial da água. Brasília: ONU, 2006.

PRADO JUNIOR, C. Formação do Brasil contemporâneo. São Paulo: Brasiliense. 1971.

SECRETARIA DE RECURSOS HIDRICOS. Plano nacional de recursos hídricos: panorama e estado dos recursos hídricos do Brasil. Brasilia: Ministério do Meio Ambiente. 2006.

SELZNICK, P. Law, society and industrial justice. New York: Russell Sage Foundation, 1969.

SILVA, J. Curso de direito constitucional positivo. São Paulo: Malheiros, 2004.

SILVESTRE, M. E. D. Código de 1934: água para o Brasil industrial. Revista Geo-Paisagem, vol. 7, n. 13, 2008.

SKIDMORE, T. Brazil: five centuries of change. Oxford: Oxford University Press. 1999.

SOARES, S.; THEODORO, H. D.; JACOBI, P. R. Governança e política nacional de recursos hídricos: qual a posição da gestão das águas no Brasil? IV Encontro Nacional da ANPPAS. Brasília: ANPPAS, 2008.

SUZIGAN, Wilson. Indústria brasileira: origem e desenvolvimento. Campinas: Hucitec, 2000.

TUCCI, C. E.; HESPANHOL, I.; CORDEIRO NETTO, O. D. Gestão da água no Brasil. Brasilia: UNESCO. 2001.

Organizações Rurais \& Agroindustriais, Lavras, v. 18, n. 4, p. 342-355, 2016 
UNESCO. Water, a shared responsibility: the united nations world water development report. Paris/Bergahahn Books: Oxford. 2006.

ÜSDIKEN, B., \& KIESER, A. Introduction: history in organization studies. Business History, vol. 46, n. 3, p. 321-330, 2004.

VIZEU, F.. Management no Brasil em Perspectiva Histórica: o projeto do IDORT nas décadas de 1930 e 1940. Tese (Doutorado em Administração). EAESP/FGV. São Paulo: 2008.
VIZEU, F. Potencialidades da análise histórica nos estudos organizacionais brasileiros. Revista de Administração de Empresas, v. 50, n. 1, p. 36-46, 2010.

VIZEU, F. Rural Heritage of early Brazilian Industrialists: its Impact on Managerial Orientation. Brazilian Administration Review, v. 8, p. 68-85, 2011.

VIZEU, F.; MENEGHETTI, F. K. ; SEIFERT, R. E. Por uma crítica ao conceito de desenvolvimento sustentável. Cadernos EBAPE.BR, v. 10, n. 6, 2012. 